Published in final edited form as:

Gastroenterology. 2018 January ; 154(2): 267-276. doi:10.1053/j.gastro.2017.07.045.

\title{
Presentation and Epidemiology of Gastroesophageal Reflux Disease
}

\author{
Joel E. Richter ${ }^{1}$ and Joel H. Rubenstein ${ }^{2,3}$ \\ 1Joy McCann Culverhouse Center for Swallowing Disorders, Division of Digestive Diseases \& \\ Nutrition, University of South Florida College of Medicine, Tampa FL \\ ${ }^{2}$ Veterans Affairs Center for Clinical Management Research, Ann Arbor, MI \\ ${ }^{3}$ Barrett's Esophagus Program, Division of Gastroenterology \& Hepatology, University of Michigan \\ Medical School, Ann Arbor, MI
}

\section{Abstract}

Gastroesophageal reflux disease (GERD) is the most prevalent gastrointestinal disorder in the United States, and leads to substantial morbidity, though associated mortality is rare. The prevalence of GERD symptoms appeared to increase until 1999. Risk factors for complications of GERD include advanced age, male sex, white race, abdominal obesity, and tobacco use. Most patients with GERD presents with heartburn and effortless regurgitation. Coexistent dysphagia is considered an alarm symptom, prompting evaluation. There is substantial overlap between symptoms of GERD and those of eosinophilic esophagitis, functional dyspepsia, and gastroparesis, posing a challenge for patient management.

\section{Keywords}

erosive esophagitis; Barrett's esophagus; esophageal stricture

By consensus, gastroesophageal reflux disease (GERD) has been defined as the effortless movement of stomach contents into the esophagus or mouth causing troublesome symptoms or complications (1). We review the clinical presentation and epidemiology of GERD. The cardinal symptoms of GERD are heartburn and regurgitation. GERD is exceedingly common, ranking as the most frequent gastrointestinal diagnosis associated with outpatient clinic visits in the United States (US), with nearly 9 million visits in 2009.(2) Although complications such as bleeding erosive esophagitis or peptic stricture are becoming less common, individuals with GERD symptoms have a decrement in their quality of life that is similar to patients with inflammatory bowel disease.(2) To accurately diagnose and manage

Corresponding Author: Joel E. Richter, MD, Professor of Medicine, Hugh F. Culverhouse Chair for Esophageal Disorders, Director, Division of Digestive Diseases \& Nutrition, Director, Joy McCann Culverhouse Center for Swallowing Disorders, University of South Florida College of Medicine, 12901 Bruce B. Downs Blvd, MDC 72, Tampa, Florida 33612, Jrichte1@ health.usf.edu.

Publisher's Disclaimer: This is a PDF file of an unedited manuscript that has been accepted for publication. As a service to our customers we are providing this early version of the manuscript. The manuscript will undergo copyediting, typesetting, and review of the resulting proof before it is published in its final citable form. Please note that during the production process errors may be discovered which could affect the content, and all legal disclaimers that apply to the journal pertain. 
GERD, it is important to recognize the epidemiologic risk factors for GERD, the variety of presenting symptoms and their relative likelihood of representing pathological reflux, and the potential for overlap with other gastrointestinal disorders.

\section{Clinical Presentation}

Heartburn and acid regurgitation are the classic symptoms of GERD. Patients generally report a burning feeling in the retrosternal area, raising into the chest and radiating toward the neck, throat and occasionally the back.(1) It occurs post-prandially-particularly after large fatty meals or the ingestion of spicy foods, citrus products, fats, chocolates, or alcohol. The supine position and bending over may exacerbate heartburn. Nighttime heartburn may cause sleeping difficulties and impair next-day function (3). Sleep deprivation as well as psychological or auditory stress may lower the threshold for symptom perception (4). GERD can be diagnosed based on symptoms, such as the occurrence of heartburn 2 or more days a week, although symptoms can be less frequent if they are troublesome and have adverse effects on well-being (1). The frequency and severity of heartburn do not associate with degree of esophageal damage.

Regurgitation has been more inconsistently described in clinical trials and epidemiological studies on GERD. Per the Montreal consensus statement, regurgitation is defined as the "perception of flow of refluxed gastric contents into the mouth or hypopharynx."(1) Among patients with daily regurgitation, lower esophageal sphincter pressure is often low; many patients have associated gastroparesis, and esophagitis is common, making this symptom more difficult to treat medically than classic heartburn (5).

The lack of a standard for the diagnosis of GERD has made it difficult to define the accuracy of the typical reflux syndrome of troubling heartburn and/or regurgitation. The Diamond Study from the United Kingdom attempted to address this question in patients presenting to family practitioners with complaints of upper gastrointestinal symptoms (6). GERD was present in 203/308 patients (66\%), based on endoscopic esophagitis and/or abnormal acid exposure or a positive symptom association probability from 24-hr pH tests. Only $49 \%$ of patients with GERD selected either heartburn or regurgitation as their most troublesome symptom, followed by dyspepsia, bloating, regurgitation, and abdominal pain or discomfort that was not characterized as dyspepsia. Sensitivity and specificity values for symptombased diagnosis of GERD were $63 \%$ and $63 \%$ by family practitioners and $67 \%$ and $70 \%$ by gastroenterologists, respectively. Questionnaires about reflux symptoms did not perform any better-they identified patients with GERD with only $62 \%$ sensitivity and $67 \%$ specificity. Nor could response of symptoms to treatment with the proton pump inhibitor (PPI) esomeprazole ( $40 \mathrm{mg}$ for 2 weeks) increase diagnostic precision-a positive response to the PPI test was observed in $69 \%$ of patients with GERD and $51 \%$ of patients without GERD (7). Similarly, a well-performed meta-analysis cast doubt on the diagnostic accuracy of the PPI trial, finding that it identified patients with GERD with $78 \%$ sensitivity and $54 \%$ specificity (8).

Less-common symptoms of GERD include dysphagia, chest pain, water brash, odynophagia, burping, hiccups, nausea, and vomiting. Dysphagia is considered an alarm symptom in 
patients with GERD that warrants upper endoscopy (9). Dysphagia usually occurs in patients with long-standing heartburn with slowly progressive dysphagia for solids. Weight loss is uncommon because patients have good appetites. The most common causes are peptic stricture and severe inflammation, but dysphagia can be the first symptom of Barrett's esophagus with esophageal cancer. The chest pain associated with GERD can be indistinguishable from that of ischemic cardiac pain. GERD is a more frequent cause of noncardiac chest pain than esophageal motor disorders.(1) The most problematic and controversial symptoms associated with GERD are chronic cough, chronic laryngitis (including hoarseness, globus sensation, and throat clearing), and asthma. Although potential mechanisms of pathogenesis have been identified, trials of medical and surgical anti-reflux treatments have produced uncertain and inconsistent results (1). Some patients with GERD are asymptomatic. This is particularly true in older patients-perhaps because of decreased acidity of the reflux material or decreased pain perception. Many older patients present first with complications of GERD because of long-standing disease with minimal symptoms. This is a particular problem for patients with Barrett's esophagus; European population studies found that $44 \%-46 \%$ of patients did not report symptoms of GERD $(10,11)$.

\section{Overlap With Other Disorders}

GERD symptoms overlap with those of other syndromes. This poses a challenge to diagnosis and can alter medical and surgical treatments.

\section{Eosinophilic esophagitis (EoE)}

The issue of how to differentiate EoE from GERD has confounded clinicians and researchers since the recognition of the disease. This diagnostic dilemma began with a pathology study of pediatric patients in 1982, which found that eosinophils in the esophageal squamous epithelium could be a manifestation of GERD, documented by 24-hr pH tests (12). Pathologists rapidly accepted the concept, and it became common clinical practice to attribute esophageal eosinophilia to GERD. The first report describing EoE as a unique syndrome, characterized by solid food dysphagia and distinct from GERD by esophageal tests, was published in 1993 (13). Subsequently, EoE was considered a chronic immune- or antigen-mediated esophageal disease. However, many cases still overlapped with GERD, so the PPI trial became the most logical and convenient means to differentiate GERD from EoE. This practice was based on the assumption that the only major effect of PPIs is to inhibit gastric acid production. Accordingly, in 2007, the American Gastroenterological Association's consensus report defined EoE as a primary disorder characterized by esophageal symptoms, esophageal biopsies with more than 15 eosinophils per high-powered field, and the "absence" of pathologic GERD—evidenced either by normal results from $\mathrm{pH}$ tests or lack of response to PPIs (14).

This mutually exclusive paradigm began to fall apart as editorials raised the possibilities of a complex interaction between GERD and EoE. These raised questions such as: does EoE cause GERD? Does GERD cause EoE? Or do these merely co-exist, because GERD is such a common disease? (15) Subsequently, Ngo et al (16) described 3 patients with EoE and significant mucosal eosinophilia who improved, based on clinical and histological features, 
after 2 months of PPI therapy. Several years later, Molina-Infante et al (17) published findings from 35 patients with mucosal eosinophilia (more than 15 eosinophils per highpowered field); $75 \%$ responded to rabeprazole ( $20 \mathrm{mg}$, twice daily) for 2 months. All 17 of the patients with GERD profile and objective acid reflux, based on endoscopy or $\mathrm{pH}$ tests, responded to this treatment. However, 50\% of the patients with an EoE-like profile and normal $\mathrm{pH}$ test results also responded to the rabeprazole.

The recognition of this condition, which was termed PPI-responsive esophageal eosinophilia (PPI-REE), caused further confusion. Studies documented that $23 \%$ to $61 \%$ of patients with symptomatic esophageal eosinophilia respond to PPI treatment (18). Furthermore, the clinical, endoscopic, histologic and even esophageal gene-expression features of PPI-REE and EoE are virtually identical (19). PPI-REE therefore resembles EoE far more than it resembles GERD.

An exciting discovery around this controversy has been the recognition that EoE and GERD could each arise via cytokine-mediated esophageal injury. In contrast to the model in which refluxed acid causes a chemical injury that destroys esophageal cells, studies from patients and animal models indicated that the esophageal damage found in patients with GERD was caused by inflammatory cells, which are attracted to the esophagus by cytokines produced by esophageal epithelial cells following exposure to refluxed acid and bile (20,21). Studies of cultured esophageal epithelial cells revealed anti-cytokine effects of PPIs that were entirely independent of effects on gastric acid production - these could heal GERD and EoE. Omeprazole was found to block eotaxin-3 secretion stimulated by T-helper 2 cytokines produced by esophageal cells from patients with EoE or GERD (22) and block secretion of interleukin 8 , a mediator of eosinophilic inflammation after exposure to acid and bile salts in esophageal epithelial cells from patients with GERD (23).

The current focus on how to distinguish EoE from GERD may therefore be counterproductive, since the 2 diseases often co-exist with complex interactions. Patients with GERD with the typical reflux syndrome associated with erosive esophagitis and hiatal hernia can have mucosal eosinophilia, which often is confined to the distal esophagus. It is not clear what proportion of patients with GERD present with these features, but it is likely to be less than $10 \%$ (24). The etiology of their mucosal eosinophilia may be secondary to direct acid injury or secondary to the effects of GERD on esophageal barrier function, which renders the epithelium permeable to food antigens and causes antigen-induced esophageal eosinophilia (25). Regardless, PPIs can reduce both mechanisms of pathogenesis; careful separation by esophageal manometry and $\mathrm{pH}$ - impedance testing is necessary for only patients who require surgical anti-reflux treatment.

\section{Functional dyspepsia}

Population-based studies have identified GERD and dyspepsia, defined as pain or discomfort centered in the upper abdomen, as some of the most common upper gastrointestinal tract symptoms-estimated prevalence values are approximately $20 \%$ for each (26). Therefore, it should not be surprising that the distinction between GERD and functional dyspepsia may not be clear cut. More than 33\% of patients with functional dyspepsia also report heartburn and acid regurgitation and vice versa. This was well illustrated in the Diamond study, in 
which $42 \%$ of the patients without GERD reported dyspepsia as their first- or second-most troubling symptom, whereas this value was $37 \%$ in patients subsequently found to have GERD (6).

Furthermore, endoscopy and $\mathrm{pH}$ tests do not separate these groups with a high level of confidence. A large systematic review of more than 5000 patients with a primary complaint of dyspepsia found endoscopic evidence of esophagitis in $13.4 \%$ of patients, followed by peptic ulcers in $8.0 \%$ (27). Several studies identified patients with functional dyspepsia using Rome II or III criteria and performed 24-hr pH tests. Tack et al (28) reported that $23 \%$ of patients with functional dyspepsia had abnormal acid exposure times, and their symptom profile was mainly epigastric pain. A similar study of an Asian population, performed by Xiao et al (29), found that $31.7 \%$ of patients had abnormal acid exposure times, with the highest percentage (48.9\%) in patients who claimed epigastric burning was their predominate symptom. In this study, the proportion of patients with a response to PPI therapy at 1 month was highest (85\%) in those with epigastric burning; the proportions were lower in patients with epigastric pain $(51.5 \%)$, postprandial distress with fullness $(66.7 \%)$, or early satiation (41.1\%). A study of 626 patients with erosive GERD treated with pantoprazole to esophagitis healing observed a $62 \%$ overlap between GERD and dyspepsia symptoms (30). Remarkably, the dyspepsia symptoms improved by $50 \%$ during PPI treatment and unlike the reflux symptoms, which usually relapsed with treatment cessation, the dyspepsia symptoms showed a trend to further decrease.

\section{Gastroparesis}

The importance of delayed gastric emptying in the pathogenesis of GERD is controversial. Early studies indicated that up to $50 \%$ of patients with reflux had delayed emptying of solids (31). However, more recent studies, using a standardized 4-hr gastric emptying test, found an overlap in $8 \%-20 \%$ of patients (32). Conceptually, impaired gastric emptying results in a greater volume of material in the stomach, which could be available to directly reflux into the esophagus or generate distension of the proximal stomach triggering transient lower esophageal sphincter (LES) relaxations. Recent studies with impedance-pH testing found that acid reflux values were not increased, but consistent with the reflux of meal contents, the increase was in post-prandial liquid or mixed reflux events and non/weakly acid reflux (33). Women and diabetics are more likely to have gastroparesis with secondary GERD. Complaints of abdominal bloating, pain, nausea, vomiting or constipation should be helpful clues and manometry often shows a normal LES pressure. Treating the gastroparesis with diet and prokinetics can alleviate the need for PPIs or anti-reflux surgery.

\section{Prevalence and Trends}

\section{Symptoms}

The pooled prevalence of at least weekly GERD symptoms reported from population-based studies worldwide is approximately $13 \%$, but there is considerable geographic variation.(34) Accurate estimates are difficult due to heterogeneity in study designs, but the prevalence of GERD appears to be highest in South Asia and Southeast Europe (more than 25\%), and lowest in Southeast Asia, Canada, and France (below 10\%) (Figure 1).(34) There are no data 
on the prevalence of GERD in Africa. In the US, estimates of the prevalence of GERD symptoms have ranged from $6 \%$ to $30 \%$, with heterogeneity related to the particular questionnaire used, including the threshold frequency and duration of symptoms required to be classified as GERD.(34) The prevalence of at least weekly GERD symptoms in the US is approximately 20\%.(35) There are approximately 110,000 hospital admissions annually in the US for GERD.(36) Importantly, the prevalence of GERD symptoms in North America, Europe, and Southeast Asia has increased approximately 50\% relative to the baseline prevalence in the early to middle 1990s, but has plateaued since then.(35) In a populationbased longitudinal study of a Norwegian county from 1995 through 2009, the annual incidence of any new GERD symptoms was $3.1 \%$, and of severe GERD symptoms was $0.2 \%$.(37) Among individuals with any GERD at baseline and excluding those who were using anti-reflux medications, symptoms resolved spontaneously in $2.3 \%$ per year; among those with severe GERD, $1.2 \%$ spontaneously resolved per year.

\section{Complications}

The predominant complications of GERD include dysphagia (including from peptic strictures, Schatzki's rings), bleeding from erosive esophagitis, and esophageal adenocarcinoma (discussed in other sections of this issue). In 3 population-based studies of patients agreeing to undergo endoscopy regardless of symptoms, the prevalence of erosive esophagitis ranged from $6.4 \%$ in China to $15.5 \%$ in Sweden.(38-40) Among individuals without symptoms of GERD, the prevalence of erosive esophagitis ranged from $6.1 \%$ in China to $9.5 \%$ in Sweden. Erosive esophagitis may frequently be a transient phenomenon. In a prospective, longitudinal study, $26 \%$ of individuals with non-erosive reflux disease at baseline were found to have erosive esophagitis on repeat endoscopy 2 years later, and in another similar study, erosive esophagitis was found in $10 \%$ of individuals 5 years later.(41 42) And among those with Los Angeles Grade A erosive esophagitis at baseline, $21 \%$ had more severe findings at 5 years.

Though death from erosive esophagitis is rare, mortality increased in the US from 1.0 per million individuals per year in 1968 through 1972 to 2.1 per million in 1988 through 1992. (43) But recurrent strictures requiring repeat endoscopic dilation in individuals with a prior dilation decreased from $16 \%$ in 1992 to $8 \%$ in 2000, possibly related to the increase in use of proton pump inhibitors.(44) From 2003 to 2006, there were approximately 10,570 hospital admissions annually for erosive esophagitis, and 14,000 admissions for esophageal stricture.(36) Esophageal adenocarcinoma is the most feared complication of GERD, and its precursor lesion, Barrett's esophagus, is also a sequella of GERD. Barrett's esophagus and esophageal adenocarcinoma are discussed in detail in other articles in this issue of Gastroenterology.

\section{Demographic Risk Factors}

There are a number of well-recognized risk factors for GERD and its complications (Table 1). In North America and in Europe, there is no association between sex and symptoms of GERD, but in South America and in the Middle East, women are approximately $40 \%$ more likely to report GERD symptoms than men.(34) There is no clear association between sex 
and esophageal stricture.(36 44) However, men are at greater risk than women for erosive esophagitis (summary odds ratio, 1.57; 95\% CI, 1.40-1.76).(45) Also men are at greater risk for Barrett's esophagus and much greater risk for esophageal adenocarcinoma than women.

Advancing age has been inconsistently associated with an increased risk for GERD symptoms. In a meta-analysis, the summary odds ratio for 50 years or more vs less than 50 years of age was 1.32 , but with an $\mathrm{I}^{2}$ value of $91.5 \%$, indicating substantial heterogeneity among study results.(34) However, advancing age is more strongly associated with complications of GERD (Figure 2).(36) Age is clearly associated with hospitalizations for esophageal strictures.(36 46) Most recently, advancing age was strongly associated with hospitalizations for erosive esophagitis.(36) However, in the late 1980s, advanced age was inversely associated with hospitalization for erosive esophagitis (odds ratio for more than 85 years vs 65-69 years of age, 0.66 ; 95\% CI, 0.65-0.67).(46) This reversal in association of age with erosive esophagitis suggests a cohort effect, whereby individuals born in an earlier generation may have been less likely to develop erosive esophagitis than later generations when they reached the same age. Such a cohort effect would most likely be explained by changes in environmental exposures (described in sections below). Esophageal adenocarcinoma is also associated with increased age, but there too, a cohort effect appears to be responsible for the increasing incidence.(47)

In the US, there appears to be similar prevalence of GERD symptoms among different races. (44 48) However, whites are at greater risk for erosive esophagitis, strictures, Barrett's esophagus, and esophageal adenocarcinoma.(36 48 49)

\section{Genetics}

Estimates of the proportion of phenotypic variance in GERD symptoms explained by genetic factors has ranged from 0 to $22 \%$.(50-52) In a twin study, $13 \%$ of the variance in GERD symptoms was estimated to be due to genetic effects, but even that proportion appeared to be mediated by anxiety and depression.(52) The genetic risk for GERD is polygenic with no individual mutation found to be significantly associated with GERD in genome wide association studies, though larger studies might yet still be able to identify statistically significant individual mutations.(50 51) Given the recent increase in prevalence of GERD symptoms relative to the broad sweep of evolutionary history, the etiology of GERD seems to be largely related to environmental exposures.

\section{Environmental Risk Factors}

Two major factors that may explain the trends are the obesity epidemic and the decreasing prevalence of Helicobacter pylori-associated gastritis. Obesity is a major risk factor for GERD symptoms, with odds ratio of 1.73.(34) Obesity is also associated with erosive esophagitis (odds ratio, 1.59), Barrett's esophagus (odds ratio, 1.24), and esophageal adenocarcinoma (odds ratio, 2.45).(53) In particular, a body distribution of abdominal obesity has been associated with complications of GERD (erosive esophagitis odds ratio, 1.87; Barrett's esophagus odds ratio, 1.98; and esophageal adenocarcinoma odds ratio, 2.51). (53) Observational studies have demonstrated that reducing the body mass index by at least 
$3.5 \mathrm{~kg} / \mathrm{m}^{2}$ increases odds for disappearance of GERD symptoms by 1.5 - to 2.4 -fold.(54)

Randomized trials have confirmed that weight loss, and in particular a decrease in waist circumference, result in improved GERD symptoms and decrease in esophageal acid exposure.(54)

Obesity is largely related to caloric excess and/or lack of physical activity, so the association of obesity with GERD and its complications could be confounded by diet or physical activity. Certain foods can induce symptoms of GERD (e.g., fatty foods, chocolate, soda pop), and obese individuals may consume those foods more regularly than non-obese individuals. However, from a cross-sectional epidemiologic study, it would be difficult to find significant associations with specific components of the diet, since many patients with GERD symptoms would naturally try to avoid those foods. There are few data from epidemiologic studies to demonstrate an association between GERD symptoms and specific foods that cause them (54 55) There have been weak associations between diets low in fruits and fiber, and high in sweets and fat with GERD symptoms.(56-60) Furthermore, a small prospective study demonstrated that even before losing substantial weight, obese patients experienced improvement in their GERD within only 6 days of initiating a low-carbohydrate diet, demonstrating that diet is an important risk factor for GERD.(61)

Likewise, the relationship between physical activity and GERD is complex. On 1 hand, certain forms of physical activity are associated with an increased risk of GERD. For instance, activities in a stooped posture, bicycle riding, weight lifting, swimming, and even surfing have been associated with increased risk of GERD, particularly during or shortly after the activity. (62-64) On the other hand, moderate, regular aerobic exercise has been inversely associated with GERD symptoms.(58 60) Physical activity at work has a positive association with GERD symptoms, and yet leisure physical activity has had a negative association with GERD symptoms.(56)

In addition to the increasing prevalence of obesity, the falling prevalence of $H$ pylori gastritis might explain the trends in GERD and its complications.(43) A proportion of patients with $H$ pylori infection develop atrophy in the gastric body and decreased gastric acid secretion. It has been proposed, therefore, that $H$ pylori infection might prevent GERD in patients who are otherwise susceptible to it. Barrett's esophagus and esophageal adenocarcinoma have been inversely associated with $H$ pylori infection - particularly the cytotoxin-associated gene A (cagA+) strain.(65 66) A meta-analysis has likewise found an inverse association between $H$ pylori and erosive esophagitis.(67) However, there is a much stronger inverse association in East Asia than in North America, and equivocal evidence for an association in Europe. Although H pylori gastritis tends to be predominantly in the gastric body in Asia, it is predominantly in the antrum in western countries.(68) Antral gastritis would be more prone to having excessive rather than diminished gastric acid secretion due to positive feedback causing corpus acid secretion. There were some early reports describing an increase in GERD symptoms following eradication of $H$ pylori,(69 70) but a subsequent meta-analysis found no such effect.(71) There is little evidence that $H$ pylori prevents symptoms of GERD in Western populations, and the inverse association between $H$ pylori with erosive esophagitis, Barrett's esophagus, and esophageal adenocarcinoma may be independent of an effect on reflux.(72) 
There are additional environmental exposures that are associated with GERD but they may not explain the trend in prevalence of GERD. For instance, tobacco use is weakly associated with GERD symptoms in cross-sectional studies (summary odds ratio, 1.26).(34) This relationship is supported by an 18-year longitudinal study, in which individuals who decreased tobacco smoking were 3-fold more likely to have reductions in symptoms of acid regurgitation and heartburn than individuals who continued to smoke tobacco.(73) Tobacco is also an important risk factor for erosive esophagitis,(74-78) and esophageal adenocarcinoma.(79 80) Though there are few data on peptic strictures, tobacco is associated with esophageal strictures in patients with endoscopic mucosal resection or with radiation therapy.(81 82)

Similarly, in observational studies, alcohol use was not strongly associated with GERD symptoms (summary odds ratio, 1.11), but there is substantial heterogeneity in results among studies.(34) Patients with GERD symptoms often report that symptoms are made worse by drinking alcohol, and randomized studies have demonstrated that ingestion of alcohol induces acid reflux more so than water. $(8384)$ Though patients often report worse symptoms with red wine than white (perhaps related to the tannins in red wine), a randomized trial found that red wine has less effect on lower esophageal sphincter relaxation and acid reflux than white wine.(85) A well-designed study did not find a positive association of current alcohol use with erosive esophagitis,(86) and there is no positive association between alcohol use and Barrett's esophagus.(87)

\section{Future Directions}

GERD is an extremely prevalent condition, and became more common up until the turn of the last century. There are several important demographic factors associated with the risk of complications from GERD, but none are strongly associated with GERD symptoms. Environmental factors are strongly related to both GERD symptoms and complications, including obesity, tobacco use, and inversely with infection with $H$ pylori. Classic symptoms of heartburn and effortless regurgitation are only modestly sensitive and specific for GERD. There is considerable overlap among GERD and gastroparesis, functional dyspepsia, and eosinophilic esophagitis, which can pose significant management dilemmas.

\section{Acknowledgments}

JHR was funded by the US Department of Veterans Affairs (I01-CX000899) and the National Institutes of Health (U01CA199336). JHR was received research funding from Shire.

\section{References}

1. Vakil N, van Zanten SV, Kahrilas P, et al. The Montreal Definition and Classification of Gastroesophageal Reflux Disease: A Global Evidence-Based Consensus. Am J Gastroenterol. 2006; 101(8):1900-20. [PubMed: 16928254]

2. Peery AF, Dellon ES, Lund J, et al. Burden of Gastrointestinal Disease in the United States: 2012 Update. Gastroenterology. 2012; 143(5):1179-87.e3. [PubMed: 22885331]

3. Johnson DA, Orr WC, Crawley JA, et al. Effect of esomeprazole on nighttime heartburn and sleep quality in patients with GERD: A randomized, placebo-controlled trial. Am J Gastroenterol. 2005; 100:1914-22. [PubMed: 16128933] 
4. Kessing BF, Bredenoord AJ, Saleh CM, Smout AJPM. Effects of anxiety and depression in patients with gastroesophageal reflux disease. Clin Gsatroenterol and Hepatology. 2015; 13:1089-95.

5. Kahrilas PJ, Jonsson A, Denison H, et al. Impact of regurgitation on health-related quality of life in gastro-oesophageal reflux disease before and after short-term potent acid suppression therapy. Gut. 2014; 63:720-726. [PubMed: 23831734]

6. Dent J, Vakil N, Jones R, et al. Accuracy of the diagnosis of GORD by questionnaire, physicians and a trial of proton pump inhibitor treatment: The Diamond Study. Gut. 2010; 59:714-21. [PubMed: 20551454]

7. Bytzer P, Jones P, Vakil N, et al. Limited ability of the proton pump inhibitor test to identify patients with gastroesophageal reflux disease. Clinical Gastroenterol and Hepatology. 2012; 10:1360-66.

8. Numans ME, Liu J, de Wit NJ, et al. Short-term treatment with proton pump inhibitors as a test for gastroesophageal reflux disease: A meta-analysis of diagnostic test characteristics. Ann Intern Med. 2004; 140:518-27. [PubMed: 15068979]

9. Fransen GA, Janssen MJ, Muris JW, et al. Meta-analysis: The diagnostic value of alarm symptoms for upper GI malignancy. Aliment Pharmacol Ther. 2004; 20:1045-52. [PubMed: 15569106]

10. Ronkainen J, Aro P, Storskrubb T, et al. Prevalence of Barrett's esophagus in the general population: An endoscopic study. Gastroenterology. 2005; 129:1825-31. [PubMed: 16344051]

11. Zagari RM, Fuccio L, Wallander MA, et al. Gastro-oesophageal reflux symptoms, oesophagitis and Barrett's oesophagus in the general population: The Loiano-Monghidoro study. Gut. 2008; 57:1354-9. [PubMed: 18424568]

12. Winters HS, Madara JL, Stafford RJ, et al. Intraepithelial eosinophils: A new diagnostic criterion for reflux esophagitis. Gastroenterology. 1982; 83:818-23. [PubMed: 7106512]

13. Attwood SE, Smyrk TC, DeMeester TR, Jones JB. Esophageal eosinophilia with dysphagia. A distinct clinicopathologic syndrome. Dig Dis Sci. 1993; 38:109-16. [PubMed: 8420741]

14. Furuta GT, Liacouras CA, Collins MH, et al. Eosinophilic esophagitis in children and adults: A systematic review and consensus recommendations for the diagnosis and treatment. Gastroenterology. 2007; 133:1342-63. [PubMed: 17919504]

15. Spechler SJ, Genta RM, Souza RF. Thoughts on the complex relationship between gastroesophageal reflux disease and eosinophilic esophagitis. Am J Gastroenterol. 2007; 102:1301-6. [PubMed: 17531015]

16. Ngo P, Furuta GT, Antonioli A, Fox VL. Eosinophils in the esophagus - peptic or allergic eosinophilic esophagitis? Case series of three patients with esophageal eosinophilia. Am J Gastroenterol. 2006; 101:1666-70. [PubMed: 16863575]

17. Molina-Infante J, Ferrande-Lamana L, Ripell C, et al. Esophageal eosinophilic infiltration responds to proton pump inhibitors in most adults. Clinical Gastroenterol and Hepatology. 2011; 9:110-17.

18. Dellon ES, Yellove V, Andreatta M, Stover J. Clinical and endoscopic characteristics do not reliably differentiate PPI responsive esophageal eosinophilia and eosinophilic esophagitis in patients undergoing upper endoscopy: A prospective cohort study. Am J Gastroenterol. 2013; 108:1854-60. [PubMed: 24145677]

19. Molina-Infante J, Bredenoord AJ, Cheng E, et al. Proton pump inhibitor - responsive oesophageal eosinophilia: An entity challenging current diagnostic criteria for eosinophilia oesophagitis. Gut. 2016; 65:524-31. [PubMed: 26685124]

20. Souza RF, Huo X, Mittal V, et al. Gastroesophageal reflux might cause esophagitis through a cytokine-mediated mechanism rather than caustic acid injury. Gastroenterology. 2009; 137:177684. [PubMed: 19660463]

21. Dunbar KB, Agoston AT, Odze RD, et al. Association of acute gastroesophageal reflux disease with esophageal histologic changes. JAMA. 2016; 315:2104-12. [PubMed: 27187303]

22. Cheng E, Zhang X, Huo X, et al. Omeprazole blocks eotaxin -3 expression by oesophageal squamous cells from patients with eosinophilic oesophagitis and GERD. Gut. 2013; 62:824-32. [PubMed: 22580413]

23. Huo X, Zhang X, Yu C, et al. In oesophageal squamous cells exposed to acidic bile salt medium, omeprazole inhibits IL-8 expression through effects on nuclear factor-kappa B and activator protein-1. Gut. 2014; 63:1042-52. [PubMed: 24048734] 
24. Kia L, Hirano I. Distinguishing GERD from eosinophilic oesophagitis: Concepts and controversies. Nature Review Gastroenterology and Hepatology. 2015; 12:379-86. [PubMed: 25986303]

25. Calabrese C, Trese D, Liquori C, et al. Esophageal cell proliferation in gastroesophageal reflux disease: Clinical - morphological data before and after pantoprazole. World J Gastroenterol. 2009; 15:936-41. [PubMed: 19248192]

26. Tack J, Talley NJ, Camilleri M, et al. Functional gastroduodenal disorders. Gastroenterology. 2006; 130:1466-79. [PubMed: 16678560]

27. Ford AC, Marwaha A, Lim A, Moayyedi P. What is the prevalence of clinically significant endoscopic findings in subjects with dyspepsia? Systematic review and meta-analysis. Clinical Gastroenterol and Hepatology. 2010; 8:830-37.

28. Tack J, Caenepeel P, Arts J, et al. Prevalence of acid reflux in functional dyspepsia and its associated symptom profile. Gut. 2005; 54:1370-6. [PubMed: 15972301]

29. Xiao YL, Peng S, Tao J, et al. Prevalence and symptom patterns of pathologic esophageal acid reflux in patients with functional dyspepsia based on Rome III criteria. Am J Gastroenterol. 2010; 105:2626-31. [PubMed: 20823838]

30. Monnikes H, Schwan T, van Rensburg C, et al. Randomized clinical trial: sustained response to PPI treatment of symptoms resembling functional dyspepsia and IBS in patients suffering from an overlap with erosive gastro-oesophageal reflux disease. Aliment Pharmacol Ther. 2012; 35:1279_ 89. [PubMed: 22486552]

31. McCallum RW, Berkowitz DM, Lerner E. Gastric emptying in patients with gastroesophageal reflux disease. Gastroenterology. 1981; 80:285-91. [PubMed: 7450419]

32. Camilleri M, Parkman HP, Shafi MA, et al. Clinical guideline: Management of gastroparesis. Am J Gastroenterol. 2013; 108:18-37. [PubMed: 23147521]

33. Gourcel G, Benanni Y, Boueyre E, et al. Influence of gastric emptying on gastro-esophageal reflux: A combined pH-impedance study. Neurogastroenterol Motil. 2013; 25:800-7. [PubMed: 23848571]

34. Eusebi LH, Ratnakumaran R, Yuan Y, et al. Global prevalence of, and risk factors for, gastrooesophageal reflux symptoms: a meta-analysis. Gut. 2017

35. El-Serag HB, Sweet S, Winchester CC, et al. Update on the epidemiology of gastro-oesophageal reflux disease: a systematic review. Gut. 2014; 63(6):871-80. [PubMed: 23853213]

36. Thukkani N, Sonnenberg A. The influence of environmental risk factors in hospitalization for gastro-oesophageal reflux disease-related diagnoses in the United States. Aliment Pharmacol Ther. 2010; 31(8):852-61. [PubMed: 20102354]

37. Ness-Jensen E, Lindam A, Lagergren J, et al. Changes in prevalence, incidence and spontaneous loss of gastro-oesophageal reflux symptoms: a prospective population-based cohort study, the HUNT study. Gut. 2012; 61(10):1390-7. [PubMed: 22190483]

38. Dent J, Becher A, Sung J, et al. Systematic Review: Patterns of Reflux-Induced Symptoms and Esophageal Endoscopic Findings in Large-Scale Surveys. Clinical Gastroenterology and Hepatology. 2012; 10(8):863-73.e3. [PubMed: 22401904]

39. Ronkainen J, Aro P, Storskrubb T, et al. High prevalence of gastroesophageal reflux symptoms and esophagitis with or without symptoms in the general adult Swedish population: a Kalixanda study report. Scand J Gastroenterol. 2005; 40(3):275-85. [PubMed: 15932168]

40. Zou D, He J, Ma X, et al. Epidemiology of symptom-defined gastroesophageal reflux disease and reflux esophagitis: The systematic investigation of gastrointestinal diseases in China (SILC). Scand J Gastroenterol. 2011; 46(2):133-41. [PubMed: 20955088]

41. Ronkainen J, Talley NJ, Storskrubb T, et al. Erosive Esophagitis Is a Risk Factor for Barrett's Esophagus: A Community-Based Endoscopic Follow-Up Study. Am J Gastroenterol. 2011; 106(11):1946-52. [PubMed: 21946284]

42. Labenz J, Nocon M, Lind T, et al. Prospective follow-up data from the ProGERD study suggest that GERD is not a categorial disease. Am J Gastroenterol. 2006; 101(11):2457-62. [PubMed: 17029609]

43. El-Serag HB, Sonnenberg A. Opposing time trends of peptic ulcer and reflux disease. Gut. 1998; 43(3):327-33. [PubMed: 9863476] 
44. El-Serag HB, Lau M. Temporal trends in new and recurrent oesophageal strictures in a Medicare population. Aliment Pharmacol Ther. 2007; 25(10):1223-9. [PubMed: 17451568]

45. Cook MB, Wild CP, Forman D. A systematic review and meta-analysis of the sex ratio for Barrett's esophagus, erosive reflux disease, and nonerosive reflux disease. Am J Epidemiol. 2005; 162(11): 1050-61. [PubMed: 16221805]

46. Sonnenberg A, Massey BT, Jacobsen SJ. Hospital discharges resulting from esophagitis among Medicare beneficiaries. Dig Dis Sci. 1994; 39(1):183-8. [PubMed: 8281855]

47. El-Serag HB, Mason AC, Petersen N, et al. Epidemiological differences between adenocarcinoma of the oesophagus and adenocarcinoma of the gastric cardia in the USA. Gut. 2002; 50(3):368-72. [PubMed: 11839716]

48. El-Serag HB, Petersen NJ, Carter J, et al. Gastroesophageal reflux among different racial groups in the United States. Gastroenterology. 2004; 126(7):1692-9. [PubMed: 15188164]

49. El-Serag HB, Sonnenberg A. Associations between different forms of gastro-oesophageal reflux disease. Gut. 1997; 41(5):594-99. [PubMed: 9414963]

50. Gharahkhani P, Tung J, Hinds D, et al. Chronic gastroesophageal reflux disease shares genetic background with esophageal adenocarcinoma and Barrett's esophagus. Hum Mol Genet. 2016; 25(4):828-35. [PubMed: 26704365]

51. Ek WE, Levine DM, D’Amato M, et al. Germline genetic contributions to risk for esophageal adenocarcinoma, Barrett's esophagus, and gastroesophageal reflux. J Natl Cancer Inst. 2013; 105(22):1711-8. [PubMed: 24168968]

52. Lembo A, Zaman M, Jones M, et al. Influence of genetics on irritable bowel syndrome, gastrooesophageal reflux and dyspepsia: a twin study. Aliment Pharmacol Ther. 2007; 25(11):1343-50. [PubMed: 17509102]

53. Singh S, Sharma AN, Murad MH, et al. Central adiposity is associated with increased risk of esophageal inflammation, metaplasia, and adenocarcinoma: a systematic review and meta-analysis. Clin Gastroenterol Hepatol. 2013; 11(11):1399-412.e7. [PubMed: 23707461]

54. Ness-Jensen E, Hveem K, El-Serag H, et al. Lifestyle Intervention in Gastroesophageal Reflux Disease. Clin Gastroenterol Hepatol. 2016; 14(2):175-82. e1-3. [PubMed: 25956834]

55. Kaltenbach T, Crockett S, Gerson LB. Are lifestyle measures effective in patients with gastroesophageal reflux disease? An evidence-based approach. Archives of Internal Medicine. 2006; 166(9):965-71. [PubMed: 16682569]

56. Zheng Z, Nordenstedt H, Pedersen NL, et al. Lifestyle factors and risk for symptomatic gastroesophageal reflux in monozygotic twins. Gastroenterology. 2007; 132(1):87-95. [PubMed: 17241862]

57. Kubo A, Levin TR, Block G, et al. Dietary patterns and the risk of Barrett's esophagus. Am J Epidemiol. 2008; 167(7):839-46. [PubMed: 18218607]

58. Nocon M, Labenz J, Willich SN. Lifestyle factors and symptoms of gastro-oesophageal reflux - a population-based study. Aliment Pharmacol Ther. 2006; 23(1):169-74. [PubMed: 16393294]

59. El-Serag HB, Satia JA, Rabeneck L. Dietary intake and the risk of gastro-oesophageal reflux disease: a cross sectional study in volunteers. Gut. 2005; 54(1):11-7. [PubMed: 15591498]

60. Nilsson M, Johnsen R, Ye W, et al. Lifestyle related risk factors in the aetiology of gastrooesophageal reflux. Gut. 2004; 53(12):1730-5. [PubMed: 15542505]

61. Austin GL, Thiny MT, Westman EC, et al. A very low-carbohydrate diet improves gastroesophageal reflux and its symptoms. Dig Dis Sci. 2006; 51(8):1307-12. [PubMed: 16871438]

62. Collings KL, Pierce Pratt F, Rodriguez-Stanley S, et al. Esophageal reflux in conditioned runners, cyclists, and weightlifters. Med Sci Sports Exerc. 2003; 35(5):730-5. [PubMed: 12750580]

63. Clark CS, Kraus BB, Sinclair J, et al. Gastroesophageal reflux induced by exercise in healthy volunteers. JAMA. 1989; 261(24):3599-601. [PubMed: 2724505]

64. Norisue Y, Onopa J, Kaneshiro M, et al. Surfing as a risk factor for gastroesophageal reflux disease. Clin J Sport Med. 2009; 19(5):388-93. [PubMed: 19741311]

65. Fischbach LA, Nordenstedt H, Kramer JR, et al. The association between Barrett's esophagus and Helicobacter pylori infection: a meta-analysis. Helicobacter. 2012; 17(3):163-75. [PubMed: 22515353] 
66. Rokkas T, Pistiolas D, Sechopoulos P, et al. Relationship between Helicobacter pylori infection and esophageal neoplasia: a meta-analysis. Clin Gastroenterol Hepatol. 2007; 5(12):1413-7. [PubMed: 17997357]

67. Raghunath A, Hungin APS, Wooff D, et al. Prevalence of Helicobacter pylori in patients with gastro-oesophageal reflux disease: systematic review. Bmj. 2003; 326(7392):737. [PubMed: 12676842]

68. Naylor GM, Gotoda T, Dixon M, et al. Why does Japan have a high incidence of gastric cancer? Comparison of gastritis between UK and Japanese patients. Gut. 2006; 55(11):1545-52. [PubMed: 16603635]

69. Schutze K, Hentschel E, Dragosics B, et al. Helicobacter pylori reinfection with identical organisms: transmission by the patients' spouses. Gut. 1995; 36(6):831-3. [PubMed: 7615268]

70. Labenz J, Blum AL, Bayerdorffer E, et al. Curing Helicobacter pylori infection in patients with duodenal ulcer may provoke reflux esophagitis. Gastroenterology. 1997; 112(5):1442-7. [PubMed: 9136820]

71. Yaghoobi M, Farrokhyar F, Yuan Y, et al. Is there an increased risk of GERD after Helicobacter pylori eradication?: a meta-analysis. Am J Gastroenterol. 2010; 105(5):1007-13. [PubMed: 20087334]

72. Rubenstein JH, Inadomi JM, Scheiman J, et al. Association between Helicobacter pylori and Barrett's Esophagus, Erosive Esophagitis, and Gastroesophageal Reflux Symptoms. Clinical Gastroenterology and Hepatology. 2013; doi: 10.1016/j.cgh.2013.08.029

73. Stake-Nilsson K, Hultcrantz R, Unge P, et al. Changes in symptoms and lifestyle factors in patients seeking healthcare for gastrointestinal symptoms: an 18-year follow-up study. Eur J Gastroenterol Hepatol. 2013; 25(12):1470-7. [PubMed: 24067605]

74. Kang SH, Lim Y, Lee H, et al. A Model for Predicting the Future Risk of Incident Erosive Esophagitis in an Asymptomatic Population Undergoing Regular Check-ups. Medicine (Baltimore). 2016; 95(4):e2591. [PubMed: 26825906]

75. Kim BJ, Cheon WS, Oh HC, et al. Prevalence and risk factor of erosive esophagitis observed in Korean National Cancer Screening Program. J Korean Med Sci. 2011; 26(5):642-6. [PubMed: 21532855]

76. Lee D, Lee KJ, Kim KM, et al. Prevalence of asymptomatic erosive esophagitis and factors associated with symptom presentation of erosive esophagitis. Scand J Gastroenterol. 2013; 48(8): 906-12. [PubMed: 23834193]

77. Matsuzaki J, Suzuki H, Kobayakawa M, et al. Association of Visceral Fat Area, Smoking, and Alcohol Consumption with Reflux Esophagitis and Barrett's Esophagus in Japan. PLoS ONE. 2015; 10(7):e0133865. [PubMed: 26225858]

78. Ou JL, Tu CC, Hsu PI, et al. Prevalence and risk factors of erosive esophagitis in Taiwan. Journal of the Chinese Medical Association: JCMA. 2012; 75(2):60-4. [PubMed: 22340738]

79. Cook MB, Kamangar F, Whiteman DC, et al. Cigarette smoking and adenocarcinomas of the esophagus and esophagogastric junction: a pooled analysis from the international BEACON consortium. J Natl Cancer Inst. 2010; 102(17):1344-53. [PubMed: 20716718]

80. Cook MB, Shaheen NJ, Anderson LA, et al. Cigarette Smoking Increases Risk of Barrett's Esophagus: An Analysis of the Barrett's and Esophageal Adenocarcinoma Consortium. Gastroenterology. 2012; 142(4):744-53. [PubMed: 22245667]

81. Francis DO, Hall E, Dang JH, et al. Outcomes of serial dilation for high-grade radiation-related esophageal strictures in head and neck cancer patients. Laryngoscope. 2015; 125(4):856-62. [PubMed: 25345779]

82. Lewis JJ, Rubenstein JH, Singal AG, et al. Factors associated with esophageal stricture formation after endoscopic mucosal resection for neoplastic Barrett's esophagus. Gastrointest Endosc. 2011; 74(4):753-60. [PubMed: 21820109]

83. Pehl C, Frommherz M, Wendl B, et al. Gastroesophageal reflux induced by white wine: the role of acid clearance and "rereflux". Am J Gastroenterol. 2002; 97(3):561-7. [PubMed: 11922547]

84. Pehl C, Wendl B, Pfeiffer A. White wine and beer induce gastro-oesophageal reflux in patients with reflux disease. Aliment Pharmacol Ther. 2006; 23(11):1581-6. [PubMed: 16696806] 
85. Pehl C, Pfeiffer A, Wendl B, et al. Different effects of white and red wine on lower esophageal sphincter pressure and gastroesophageal reflux. Scand J Gastroenterol. 1998; 33(2):118-22. [PubMed: 9517519]

86. Anderson LA, Cantwell MM, Watson RG, et al. The association between alcohol and reflux esophagitis, Barrett's esophagus, and esophageal adenocarcinoma. Gastroenterology. 2009; 136(3):799-805. [PubMed: 19162028]

87. Thrift AP, Cook MB, Vaughan TL, et al. Alcohol and the risk of Barrett's esophagus: a pooled analysis from the International BEACON Consortium. Am J Gastroenterol. 2014; 109(10):158694. [PubMed: 25047401] 


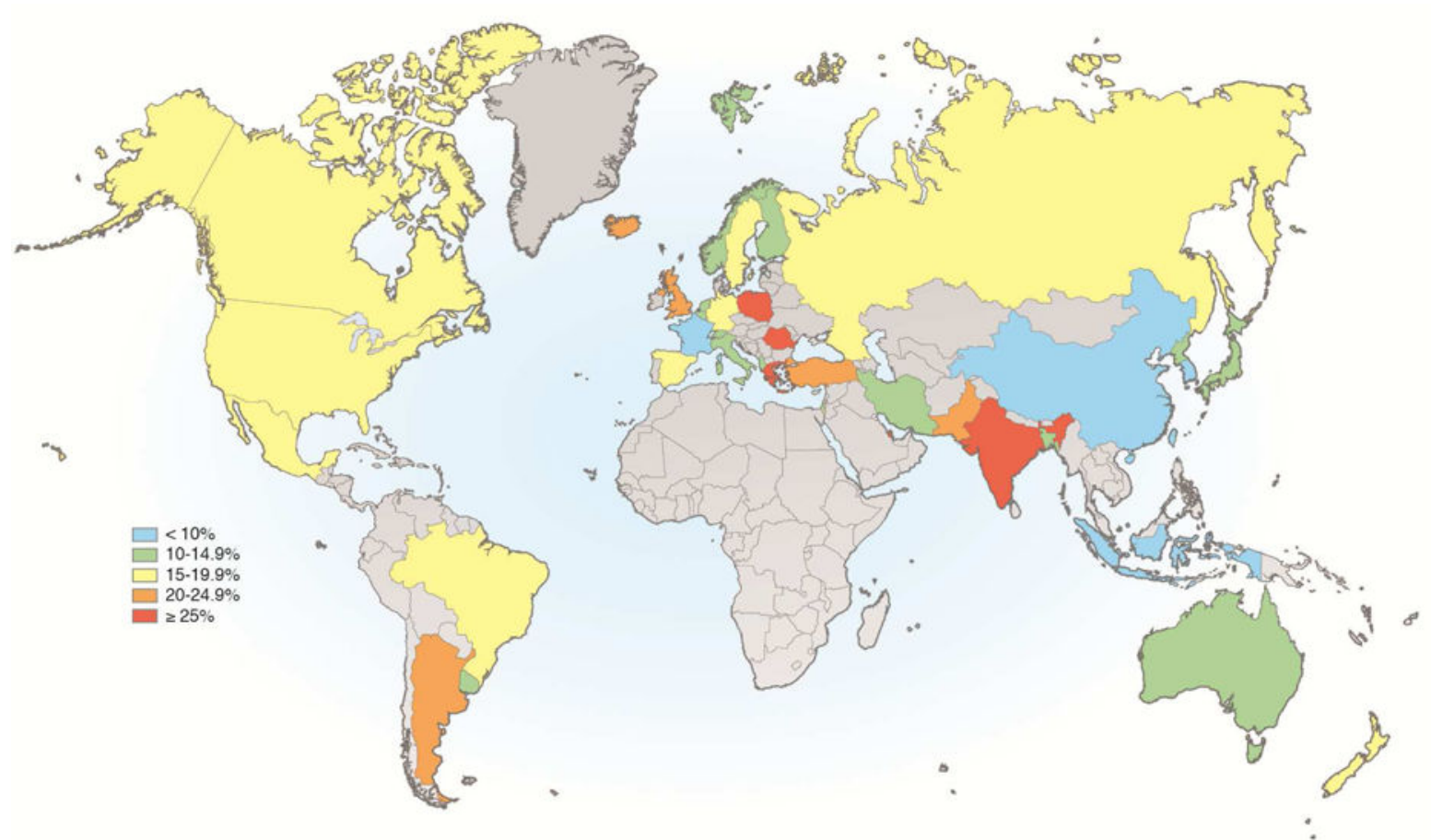

Figure 1. Prevalence of weekly gastroesophageal reflux symptoms worldwide, based on symptoms at a frequency of once a week or more

(Adapted from Eusebi, et al. Gut. 2017. doi: 10.1136/gutjnl-2016-313589)(34) 

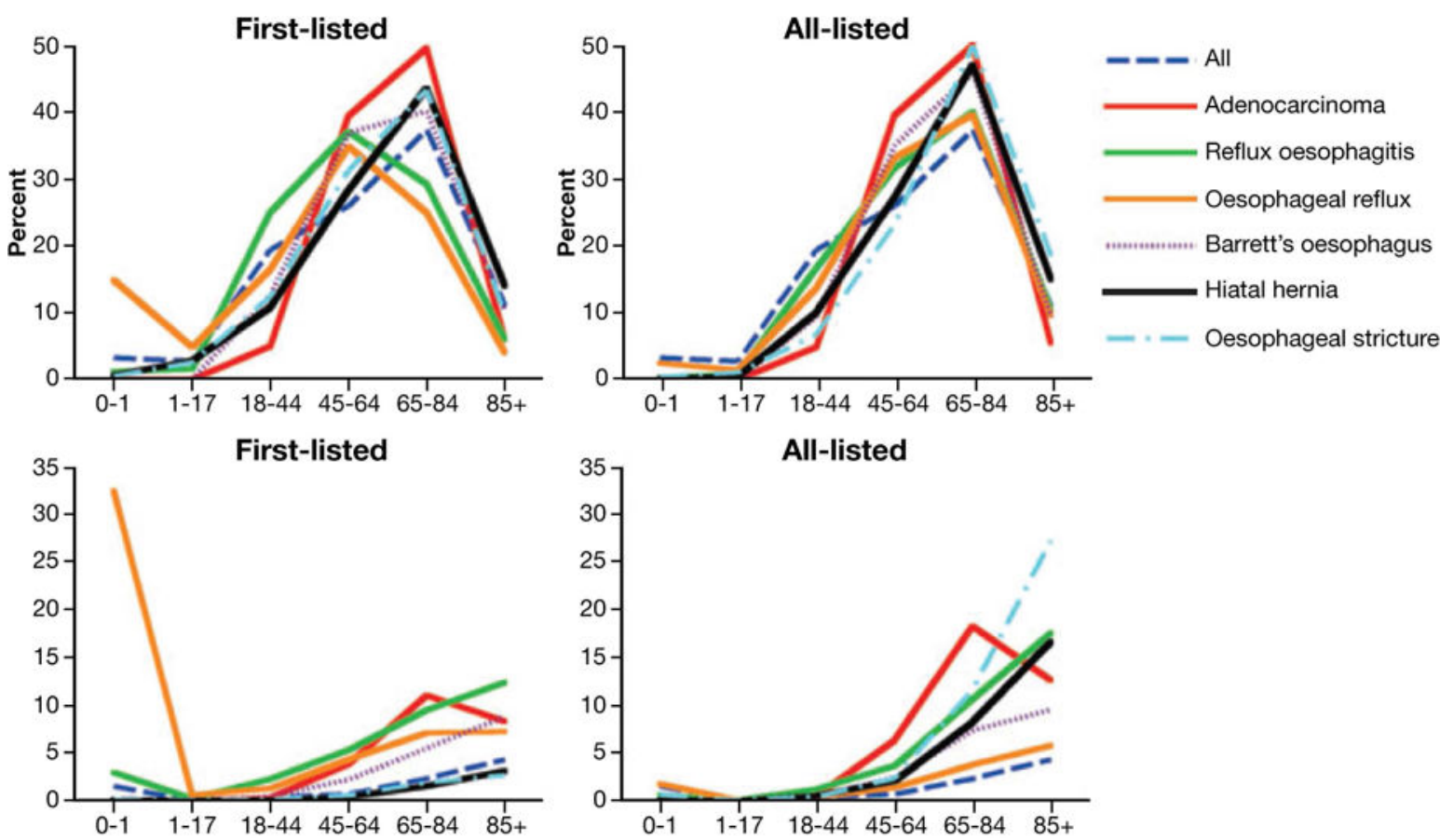

Figure 2. Age distribution of GERD-related US hospitalization discharge diagnoses

Upper graphs: age fractions expressed as percent of all patients with a given diagnosis. Lower left graph: age-specific rates of first-listed adenocarcinoma per 100 000, reflux esophagitis per 100 000, esophageal reflux per 10 000, Barrett's esophagus per 100000 , hiatal hernia per 10 000, and esophageal stricture per 10000 US population. Lower right graph: age-specific rates of all-listed adenocarcinoma per 100 000, reflux esophagitis per 10 000, esophageal reflux per 10 000, Barrett's esophagus 10 000, hiatal hernia per 1000, and esophageal stricture per 10000 US population. (From Thukkani N. \& Sonnenberg A., Alimentary Pharmacology and Therapeutics. 2010;31(8):852-61).(36) 


\section{Table 1}

Risk Factors for GERD and Complications

\begin{tabular}{|l|l|l|l|l|}
\hline Risk Factor & Symptoms & Esophagitis & Stricture & Esophageal Adenocarcinoma \\
\hline Age & +- & + & + & ++ \\
\hline Male Sex & $+/-$ & + & $+/-$ & ++ \\
\hline White Race & $+/-$ & + & + & ++ \\
\hline Obesity & + & + & & ++ \\
\hline H pylori & $+/-$ & - & & - \\
\hline Tobacco & + & + & + & ++ \\
\hline
\end{tabular}

${ }^{+}$: positive association

${ }^{++}$: strongly positive association

$\overline{-}$ : negative association

- : strongly negative association

$+/-$

: no association or heterogeneous findings for association 